\title{
Cotejando capacidades burocráticas e políticas como ação: um estudo comparativo de desenvolvimento e impactos em quatro órgãos do Executivo Federal brasileiro
}

\author{
Alexander Cambraia Nascimento Vaz \\ Doutor em Ciência Política pela Universidade Federal de Minas Gerais \\ Pesquisador do International Policy Centre for Inclusive Growth
}

cambraia04@gmail.com

Resumo

$\mathrm{O}$ artigo investiga os condicionantes institucionais para o desenvolvimento de capacidades políticas e burocráticas pelas instituições governamentais, bem como em que medida e sentido a combinação desses dois elementos impacta os seus processos de formulação e implementação de políticas públicas. Realiza-se estudo comparativo de quatro instituições do poder Executivo Federal brasileiro, buscando, através de seus respectivos percursos históricos de formação, elementos explicativos para sua situação atual em termos dessas capacidades. Em adição, realiza-se estudo de programas desenvolvidos por essas próprias instituições, entrevendo em que sentido seu status corrente de capacidades tende a influenciar o desenvolvimento desses programas. A análise evidencia que a área temática de atuação dos órgãos tem importante influência no seu potencial de desenvolvimento das capacidades estudadas. Ademais, o desenvolvimento conjunto dessas últimas parece levar à obtenção de resultados satisfatórios no desenvolvimento de políticas por esses órgãos.

Palavras-chave: capacidades estatais, capacidades burocráticas, capacidades políticas, interfaces socioestatais, desenvolvimento socioeconômico.

\section{Introdução}

O desenvolvimento de capacidades burocráticas e políticas tem sobressaído como variável determinante e condicional ao desempenho das burocracias governa- 
mentais no âmbito dos seus processos executivos de tomada de decisão e gestão em políticas públicas (Evans; Rueschemeyer; Skocpol, 1985; Jonhson, 1995; Evans, 1995; Leftwich, 1998; Rauch; Evans, 2011; Cardoso Jr., 2012). A análise e observação das instituições e organizações que subjazem os entes estatais permite entrever, nas suas conformação e dinâmica operacionais, variações importantes no desenvolvimento efetivo e nos efeitos estruturais passíveis de associação a essas capacidades (Howlett; Ramesh, 2003; Painter; Pierre, 2005; Pires; Vaz, 2014; Pires; Gomide, 2016). Já se sabe, por exemplo, que, a diferentes combinações dessas últimas, tendem a corresponder distintas repercussões na apresentação de resultados na seara administrativa por parte dos órgãos estatais (Barreto; Vaz; Jannuzzi, 2012; Ramesh; Howlett, 2015). Uma vez desenvolvidas em conjunto, já há evidências de existir não apenas um reforço mútuo entre ambas, mas, também, a geração de incrementos significativos nos potenciais das burocracias de atingirem resultados satisfatórios no âmbito de políticas e ações dessa natureza (Vaz, 2016).

A investigação desses elementos tem contribuído sobremaneira à avaliação do desempenho técnico e operacional dos Estados, revelando-se debate notadamente proficuo no campo de estudos e análises da administração pública gerencial (Vaz, 2015). A despeito disso, algumas questões ainda têm sido pouco ou mesmo modicamente exploradas dentre o seu arcabouço analítico constitutivo. Duas dessas questões despontam como prementes nessa linha. Primeiro, a investigação dos fatores e/ou mecanismos associados ao desenvolvimento das capacidades no âmbito das instituições públicas, especialmente no que tange às diferenças e similaridades advindas desse processo e seu impacto nas conformações institucional e administrativa de cada órgão. Segundo, a averiguação da forma pela qual os distintos arranjos organizacionais resultantes desse processo repercutem no trabalho das instituições que o levam a cabo, particularmente no que tange aos resultados apresentados por essas instituições na gestão de políticas públicas.

Esse artigo se dedica a investigar ambas as questões, tomando-as por objeto base de sua linha argumentativa eestrutura de análise, conjuntamente. Sugere-se que a área temática subjacente à atuação dos órgãos públicos tenha papel central no recrudescimento de suas respectivas capacidades burocráticas e políticas, porque capaz de expô-los a diferentes constrangimentos, tanto na senda de suas formações burocráticas, quanto nas relações que estabelecem com agentes não estatais. Como consequência disso, a geração de produtos e ações a partir do arcabouço institucional daí resultante tende a sofrer os mesmos tipos de constrangimentos, levando esses órgãos a apresentarem variações nos seus resultados efetivos e nos efeitos esperados de suas ações.

A estratégia metodológica adotada se baseia no estudo e comparação de casos, a qual conta com recorrente utilização nas ciências sociais de uma forma geral (Yin, 2001). Compara-se quatro instituições da administração direta do poder Executivo Federal brasileiro, tendo por base os seus respectivos prognósticos de desenvolvimento das capacidades elencadas vis-à-vis os relacionamentos estabelecidos com outros atores no âmbito desse processo, bem como os resultados alcançados em programas empreendidos nos seus entremeios. Os dados utilizados foram coletados através de documentos oficiais dos 
próprios órgãos e programas analisados, bem como porentrevistas realizadas com gestores públicos responsáveis por cada qual, além dos trabalhos deVaz (2016) e Pires e Vaz (2014).

Em adição a essa breve introdução, o texto se organiza em mais quatro seções. $\mathrm{Na}$ primeira, discute-se os conceitos de capacidades políticas e burocráticas, com foco na importância de sua articulação no âmbito da gestão e nos resultados apresentados pela administração estatal na operacionalização de políticas públicas. A segunda seção tem caráter metodológico, estabelecendo as estratégias analíticas para o estudo, bem como justificando a escolha efetiva de casos para análise. A terceira seção se dedica à investigação dos condicionantes ao desenvolvimento das capacidades burocráticas e políticas dentre os órgãos tomados como objeto de trabalho. Na quarta seção, realiza-se aprofundamento dessa análise, cotejando, para cada órgão, a relação entre as capacidades desenvolvidas por cada qual e os resultados apresentados por programas específicos elegidos para estudo no âmbito de suas intervenções e ações. A quinta e última seção é dedicada às considerações finais.

\section{O foco na variabilidade de capacidades}

As análises e estudos acerca do papel do Estado nos âmbitos socioeconômico e de gestão de políticas públicas nos informam a relevância da atuação desse ator para o desenvolvimento das sociedades de uma forma geral (List, 1986; Ribeiro et al., 2006; Bresser-Pereira, 2011; Albuquerque, 2013). Do ponto de vista operacional, essa atuação se daria sob a alcunha e determinância de dois elementos institucionais específicos (Skocpol; Amenta, 1986; Leftwich, 1995). Em primeiro lugar, a necessidade de cooperação e estabelecimento de parcerias com agentes socioeconômicos privados originários do setor empresarial (Furtado, 1998). O assentamento dessa colaboração se fundaria como condição para implementação dos planos e projetos governamentais na seara das políticas públicas, uma vez que ao agente estatal seria prescindível dispor da totalidade, ou, ainda, da exclusividade, dos meios e recursos necessários para o desempenho dessa função (Sylla, 1992).

Em segundo lugar, talvez mais importante, a premência de se garantir a independência dos atores estatais frente às investidas e interesses dos agentes econômicos privados com os quais, porventura e eventualmente, parcerias fossem estabelecidas (Johnson, 1984). Segundo Rueschemeyer e Evans (1985), face o poder político-decisório centrado na figura estatal, não seria dificil esperar que esses agentes econômicos buscassem se apropriar desse poder, tendo por fulcro a conformação e a concretização de seus próprios objetivos na seara socioeconômica. O trunfo da atuação estatal, nessa linha, se embasaria na faculdade da burocracia de fomentar o estabelecimento e a concretização de parcerias no âmbito privado, ao mesmo tempo em que conseguisse preservar e manter sua autonomia no âmbito sociopolítico (Evans, 1995).

Autores de distintas matizes e filiações teóricas, como a ciência política (Hendrix, 2010), a sociologia (Skocpol, 1979), dentre outras, vêm delineando conjecturas e reflexões sobre os elementos que atuariam como potencializadores e balizadores dessa faculdade. 
Um dos vieses mais difundidos e aceitos tem se fundamentado na chamada hipótese weberiana estatal (Evans; Rauch, 2000), que arbitra a operação do Estado sob os auspícios de uma burocracia altamente profissionalizada, com habilidades técnicas para implementação de políticas públicas e guarnecida por dada autonomia operacional no âmbito das instituições que lhe subjazem (Johnson, 1984; Chang, 2003; Evans, 2004; Ramesh; Howlett, 2015). Quão maior o reforço desses ativos, ou dessas capacidades burocráticas, maiores seriam as chances do Estado de aperfeiçoar seus potenciais de gestão e, principalmente, de apresentação de resultados no âmbito da operacionalização de políticas públicas por ele eventualmente erigidas (Ramesh; Howlett, 2015).

As investigações empíricas que serviram de base a essas reflexões e que induziram, a partir de suas evidências e prognósticos, a composição dessa correlação, estruturaram-se em torno de condições históricas e contextuais bastante específicas e particulares (Evans, 2004). Duas dessas condições estariam no cerne da estrutura argumentativa e do marco-lógico operacional da literatura que se concretizou tendo por pilar esses estudos. Em primeiro lugar, a adoção, na maioria dos Estados tomados por objeto de investigação, de um sistema político diferente daquele que, já na década de 1960, encontrava-se em franca expansão por grande parte dos países, que é a democracia (Santos; Avritzer, 2002). E, em segundo lugar, nos casos estudados nos quais esse sistema foi adotado, o foco na sua concepção estrito-procedimental (Schumpeter, 1976), voltada à instituição do voto como elemento exclusivo para resolução do problema agente-principal na política (Leftwich, 1998).

Sem embargo da relevância das contribuições teórico-analíticas trazidas à baila por essa literatura, as circunstâncias históricas e contextuais contemporâneas sob as quais o ator estatal tem sido instado a agir recobrem-se de elementos condicionantes e balizadores que lhes são efetiva e factualmente estranhos (Vaz, 2015). A base normativo-operacional estruturadora dessas circunstâncias - e, por conseguinte, dos elementos a elas circunscritos - se fundaria numa busca por maior proximidade e contiguidade entre o Estado e o conjunto da população na gestão de políticas públicas, tanto em países do "Sul”, quanto do "Norte" (Santos; Avritzer, 2003). Em seu âmago, restaria uma procura por maior transparência e responsividade no que toca às ações estatais, sendo os governos cada vez mais demandados a compartilhar efetivamente com a sociedade o poder decisório que irá gerar as ações e as atividades delineadoras dos seus próprios projetos e ações (Miguel, 2005).

Diversos estudos já vêm sendo erigidos com fulcro nesse modo de operação e atuação do Estado, tendo por base os processos de gestão e desenvolvimento de políticas públicas (Coelho; Nobre, 2004; Lavalle; Houtzager; Castello, 2006; Vaz, 2011). Essas investigações vêm se apropriando da temática sob diferentes vieses e perspectivas de análise, como os estudos sobre accountability e responsiveness (Peruzzotti, 2006; Sintomer, 2010), os estudos sobre participação política e controle social (Avritzer, 2009), os estudos sobre interfaces socioestatais (Pires; Vaz, 2014;Vaz, 2015), dentre outros.Via de regra, suas ilações sugerem que, ao considerar as concepções e perspectivas dos atores socioeconômicos não-estatais, geralmente mais próximos das questões e dos problemas a serem endereçados pelas políticas públicas, tão mais aprimorada restaria a racionalidade do Estado para o equacionamento dos 
custos de transação inerentes aos processos públicos de tomada de decisão erigidos na senda democrática1 (Miguel, 2005;Vaz, 2011; Avritzer, 2015; Lavalle; Szwako, 2015).

A despeito de suas relevância e congruência normativas, a operacionalização e/ou efetivação dessas ilações tenderia a impor, uma vez levada a cabo, vale dizer, significativos desafios às burocracias no plano concreto das ações (Boschi; Gaitán, 2008). O principal e mais expressivo desses desafios consiste na concepção e no estabelecimento efetivo de uma institucionalidade burocrático-instrumental capaz de guarnecer os Estados com recursos e procedimentos operacionais factíveis e suficientemente adequados para o desempenho dessa tarefa (Evans, 2011;Vaz, 2016; Pires; Gomide, 2016). Esse seria o cerne do arcabouço operacional de atuação sociopolítica e econômica dos Estados nesse "novo tempo" (Bresser-Pereira, 2013): o processo de busca e efetivação deformas e canais para se conferir maior permeabilidade das ações estatais às demandas das sociedades,consubstanciado institucionalmente como método basilar e prática contumaz de gerenciamento e administração governamentais (Pires; Vaz, 2014).

Uma vez confrontada com esse arcabouço, a concepção clássica de ação estatal, embasada exclusivamente nas capacidades burocráticas como substrato executivo e operacional do Estado, acaba por se revelar limitada nas suas concretude e factibilidade práticas (Evans, 2011). Não obstante a relevância aportada a seu desenvolvimento e aprimoramento no âmbito da administração gerencial, essa concepção não prevê elementos específicos na sua estrutura que deem conta desses "novos" processos e ações institucionais. As condições sociopolíticas atuais impostas à atuação estatal exigiriam do ator, na verdade, para além do aperfeiçoamento dessas capacidades, o desenvolvimento de capacidades políticas como forma de garantir legitimidade à sua laboração executiva. Tais capacidades, vale dizer, não estariam restritas à mera perspectiva de parceria com grupos econômicos privados (Evans, 1995), à mestriana gestão de conflitos entre tais grupos (Chang, 1995), ou, ainda, à busca de meta-instituições capazes de, pragmaticamente, sistematizar seus respectivos processos de interação (North, 2003).

As capacidades políticas se expressariam, sobretudo, na busca constante por sinergias e concertações com os diversos movimentos e grupos da sociedade, à guisa do campo temático objeto de trabalho do Estado (Vaz, 2015). Isso quer dizer que ao ator estatal caberia a tarefa de estabelecer interações com os diversos setores associados a seus projetos de desenvolvimento, independentemente se vinculados estritamente à esfera econômica, ou ligados a outras esferas de atuação social, como meio-ambiente, proteção social, educação, movimentos de base, dentre outros. Assim, necessário seria ao Estado o estabelecimento de negociação com os diversos grupos que compõem o tecido social para a gestão das políti-

1 Naturalmente, existem perspectivas contrárias a essa concepção, ainda que pouco afetas ao debate sobre legitimidade da ação estatal. White (1998), por exemplo, observa que a democracia implicaria trade-off entre a políticas de modernização industrial e a necessidade de redirecionamentos de fontes de investimento a outros tipos de políticas. O desenvolvimentismo, segundo Leftwich (1998), implicaria conferir tal ritmo às mudanças sociais e econômicas que seria incompatível à democracia. 
cas públicas, e não apenas com aqueles de caráter estritamente econômico e supostamente estratégicos aos projetos prioritários no seu âmbito operacional e de ação gerencial.

De fato, quando analisamos a dinâmica burocrático-política a partir desse ponto de vista, notamos efeitos significativos para os processos de formulação e produção de políticas públicas de uma maneira geral. Uma vez desenvolvidas, em conjunto, capacidades políticas e burocráticas pelas instituições governamentais, por exemplo, parece haver pelo menos dois efeitos importantes. Em primeiro lugar, os resultados alcançados pelas burocracias que adotam tal procedimento tendem a ser qualitativa e quantitativamente melhores do que aquelas em que o desenvolvimento se dá de maneira isolada (Pires; Gomide, 2016). Em segundo lugar, observa-se uma tendência de mútuo recrudescimento - e não de conflito - entre ambas (Vaz, 2016).

Assim, parece que políticas que contêm ambos os tipos de capacidades tendem a ser mais propensas não sóà adoção de medidas voltadas ao aprimoramento da ação estatal, mas, também, à conformação de processos de mútua retroalimentação entre essas duas institucionalidades. Isso expressa fortemente a relevância e a premência de se investigar, no âmbito dos órgãos públicos, os condicionantes institucionais e as dinâmicas operativasque permitem às burocracias desenvolverem, em graus variados, tais capacidades. Além disso, revela a importância de se investigar, também, os efeitos passíveis de associação a essas últimas nos potenciais de ação e nos resultados efetivamente apresentados por esses órgãos no tocante a políticas e processos estatais sob sua administração e gerência.

Sugere-se, no artigo, que um dos principais condicionantes estruturais à atuação estatal nessa linha consiste na área temática subjacente e objeto de operação das instituições públicasquando de seu desenvolvimento organizacional. A área temática de atuação expõe esses órgãos a diferentes constrangimentos no âmbito de suas respectivas trajetórias histórica e de formação institucional, tendo por baseas relações que estabelecem com, bem como, em especial, as influências e demandas que recebem de entidades e grupos de caráter não-estatal.

Vez que dotados, cada qual, de distintos recursos de poder e influição, a atuação dessas entidades e grupos causa efeitos diversos nas estruturas corporativa, normativa e de abertura social dos órgãos públicos, gerando, nos seus entremeios, capacidades políticas e burocráticas que se afiguram sob diferentes vieses, graus e escalas. Em adição, bem como em consequência disso, a geração de produtos e ações, tais como políticas e programas setoriais, a partir do arcabouço institucional daí resultante, tende a sofrer os mesmos tipos de constrangimentos, levando esses órgãos a apresentarem variações nos seus resultados efetivos e efeitos esperados de suas ações. As próximas seções se ocupam do tratamento de ambas as questões.

\section{Estratégia analítico-metodológica}

Como forma de defrontar e tratar essas indagações, esse trabalho toma por estratégia analítico-metodológica a comparação de órgãos advindos e pertencentes à administração público-estatal. Busca-se investigar os seus respectivos prognósticos de desenvolvimento 
de capacidades políticas e burocráticas vis-à-vis os relacionamentos estabelecidos com outros atores no âmbito desse processo. Em adição, busca-se entrever os resultados alcançados em políticas públicas empreendidas nos seus entremeios. Analiticamente, chama-se atenção para a importância da investigação focada nos percursos institucionais pelos quais os atores sociais trocam experiências, valores, interesses e preferências ao longo das interações que estabelecem entre si, remodelando suas próprias decisões e perspectivas no âmbito desse processo (Rodrik, 2004).

Retira-se, nesse sentido, a centralidade da observação e do estudo focados exclusivamentenos resultados dos processos interativos, lançando-se luz muito mais nas dinâmicas de construção e de manutenção rotineira dos relacionamentos estabelecidos entre esses atores (Edigheji, 2010; Evans, 2011). Metodologicamente, o procedimento base de investigação se funda na técnica de estudo comparativo de casos, utilizada de maneira recorrente nas Ciências Sociais de uma forma geral (Yin, 2001). São dois os componentes centrais dessa metodologia: a escolha efetiva de casos a serem investigados, por um lado; e o estabelecimento de parâmetros de comparação entre tais casos, por outro.

No que tange à questão inicial de pesquisa, relativa à correlação entre área temática de trabalho e o grau e sentido do desenvolvimento de capacidades políticas e burocráticas pelos órgãos públicos, a escolha efetiva dos casos a serem analisados se deu com base na investigação de Vaz (2016). O autor elabora, a partir de variáveis e indicadores selecionados, para o período 2004 a 2009, dois índices de mensuração para tais capacidades no âmbito de órgãos da administração direta do poder Executivo Federal brasileiro. Com base nesses índices, realiza trabalho de classificação dessas instituições em categorias de alta, média e baixa capacidades, tanto burocráticas, quanto políticas. Para os fins desse estudo, decidiu-se eleger para análise casos advindos desse conjunto de organismos investigado pelo autor, a partir de três critérios específicos.

O primeiro critério fundou-se na existência de temáticas diferenciadas de atuação por cada instituição analisada. Isso possibilitaria entrever se, efetivamente, a área de atuação poderia ser associada aos potenciais de desenvolvimento de capacidades políticas e burocráticas por cada uma, bem como em que medida isso seria concretizado. O segundo critério concerniu à existência de informações por parte dessas instituições, tendo sido dada preferência àquelas que contavam com registros e históricos robustos e de fácil acesso. $\mathrm{O}$ último critério fundou-se nas capacidades expressas por cada organismo investigado, tendo por base os dados compilados pelo autor. Por um lado, foram elegidos órgãos dentre aqueles que, ao longo do período da pesquisa, mostraram-se capazes de melhorar sua posição no âmbito da tipologia estabelecida pelo estudo. E, por outro lado, foram elegidos outros dentreaqueles que não foram capazes de fazer tal movimento.

Tendo por base esses critérios, bem como ponderando o total de casos a serem analisados no âmbito desse artigo, foram elegidos no total quatro órgãos para estudo (Quadro 1): o Ministério do Desenvolvimento Social e Combate à Fome (MDS); o Ministério da Educação (MEC); o Ministério da Integração Nacional (MINA); e o Ministério dos Esportes (ME). Inicialmente, no primeiro ano pesquisado pelo autor, esses quatro órgãos 
mostravam baixas capacidades políticas e burocráticas no domínio de suas ações e operações. Já ao final do período analisado, dois foram capazes de ascender à categoria de altas capacidades (MDS e MEC) e os outros dois permaneceram na categoria de baixas capacidades (MINA e ME).

Quadro 1 - Condição de desenvolvimento institucional dos Órgãos elegidos para análise, segundo ano de observação - Brasil 2004/2009

\begin{tabular}{|c|c|c|}
\cline { 1 - 2 } \multicolumn{1}{c|}{ MDS } & $\begin{array}{c}\text { Baixa capacida- } \\
\text { de burocrática } \\
\text { Baixa capacidade política }\end{array}$ & $\begin{array}{c}\text { Alta capacidade burocrática } \\
\text { Alta capacidade política }\end{array}$ \\
\cline { 1 - 2 } MEC & $\begin{array}{c}\text { Baixa capacida- } \\
\text { de burocrática } \\
\text { Baixa capacidade política }\end{array}$ & $\begin{array}{c}\text { Baixa capacida- } \\
\text { de burocrática } \\
\text { Baixa capacidade política }\end{array}$ \\
\hline
\end{tabular}

Fonte:Vaz, 2016.

Como forma de comparar as instituições elegidas para investigação, três parâmetros analíticos foram trazidos à baila (Quadro 2). A adoção desses parâmetros se dá de maneira a entrever os principais condicionantes envolvidos no processo de desenvolvimento de capacidades por cada qual, vis-à-vis a hipótese de pesquisa aventada.

Quadro 2 - Parâmetros de análise dos órgãos elegidos para estudo

\begin{tabular}{|c|c|}
\hline $\begin{array}{c}\text { Corpo- } \\
\text { rativo }\end{array}$ & $\begin{array}{c}\text { Relacionado ao desenvolvimento institucional das instituições, especial- } \\
\text { mente em termos de aquisição de ativos ligados à capacidade burocráti- } \\
\text { ca, como composição e caracterização de um corpo técnico próprio }\end{array}$ \\
\hline Societal & $\begin{array}{c}\text { Relacionado à interação entre movimentos de cunho social em áreas de po- } \\
\text { líticas públicas específicas e o desenvolvimento institucional da burocracia, } \\
\text { assim como às relações institucionais que este último estabelece com inter- } \\
\text { faces socioestatais específicas (PIRES;VAZ, 2014) ao longo de sua história }\end{array}$ \\
\hline $\begin{array}{c}\text { Norma- } \\
\text { tivo }\end{array}$ & $\begin{array}{c}\text { Relacionado às regras e normativas gerais que guiaram o desenvol- } \\
\text { vimento da instituição, especialmente em termos de constrangimen- } \\
\text { tos de ações e configurações de sistemáticas de funcionamento }\end{array}$ \\
\hline
\end{tabular}

Fonte: elaboração própria, 2014.

A segunda questão de pesquisa suscitada no trabalho concerne à relação entre as capacidades instaladas dos órgãos e seus respectivos potenciais de resposta em termos de formulação e produção de políticas públicas. Sugere-se que, em função das diferentes combinações de capacidades políticas e burocráticas resultantes dos processos de formação organizacional de cada instituição, variações sejam aferidas nos seus resultados efetivos e nos efeitos esperados de suas ações. Nesse caso, a escolha de casos se voltou a programas desenvolvidos pelos órgãos já elegidos para estudo, a partir de dois critérios de seleção. 
O primeiro critério concerniu à implementação e existência efetiva do programa ao longo de todo o período considerado, sem interrupções. Esse critério é importante especialmente porque garante a existência de dados para análise e que não houve eventos significativos capazes de interromper a execução de cada um. O segundo critério para escolha concerniu à possibilidade de se encontrar os agentes que, em algum momento, foram responsáveis por sua gestão. A partir disso, quatro programas foram elegidos: Programa de Erradicação do Trabalho Infantil (PETI), concernente ao MDS; Programa Brasil Alfabetizado (PBA), do MEC; Programa de Desenvolvimento da Agricultura Irrigada (PDAI), concernente ao MINA; e o Programa Segundo Tempo (PST), concernente ao ME. Como forma de comparar esses programas, dada a hipótese de trabalho, foram elencados quatro parâmetros de investigação (Quadro 3).

Quadro 3 - Parâmetros de análise dos programas elegidos para estudo

\begin{tabular}{|c|c|}
\hline $\begin{array}{c}\text { Objetivos e } \\
\text { Resultados }\end{array}$ & $\begin{array}{c}\text { Capta a percepção do gestor acerca da relação entre os objeti- } \\
\text { vos originalmente traçados pelo Programa e os resultados alcan- } \\
\text { çados dentre o período de sua permanência na administração }\end{array}$ \\
\hline $\begin{array}{c}\text { Recursos e } \\
\text { Estratégias }\end{array}$ & $\begin{array}{c}\text { Capta a percepção do gestor acerca da qualidade, ade- } \\
\text { quabilidade e comprometimento do corpo técnico }\end{array}$ \\
\hline $\begin{array}{c}\text { Negociação } \\
\text { e Imple- } \\
\text { mentação }\end{array}$ & $\begin{array}{c}\text { Capta a percepção do gestor acerca do grau de com- } \\
\text { plexidade envolvido na conformação de atores e recur- } \\
\text { sos para a implementação e gestão efetiva do programa }\end{array}$ \\
\hline $\begin{array}{c}\text { Abertura } \\
\text { e Acesso }\end{array}$ & $\begin{array}{c}\text { Capta a percepção do gestor acerca do grau de abertura passível de } \\
\text { atribuição ao Programa em termos de interfaces sócio-estatais }\end{array}$ \\
\hline
\end{tabular}

Fonte: elaboração própria, 2014.

As fontes de dados utilizadas advieram de documentos oficiais dos próprios órgãos e programas analisados. Em adição, foram realizadas entrevistas com gestores de cada programa, de maneira a se buscar conhecer o seu funcionamento, assim como avanços e limites na sua implementação ${ }^{2}$. Os gestores foram procurados de acordo com sua presença no âmbito de gestão do Programa em qualquer ano da amostra, desde que ele tenha ficado responsável pela gestão pelo período de pelo menos um ano corrido. A avaliação de sua percepção foi importante no sentido de fornecer dicas acerca das principais variações de resultados apresentados pelas burocracias no âmbito de suas operações.

\section{Analisando o desenvolvimento institucional dos Órgãos}

A observação das capacidades políticas e burocráticas subjacentes aos órgãos aqui elegidos para análise levanta o questionamento acerca dos motivos que os levaram a sair, conjuntamente, de uma situação similar no primeiro ano investigado em Vaz (2016), mas,

O guia utilizado para entrevista encontra-se no Anexo A. No total foram realizadas oito entrevistas, sendo duas por programa. 
no último ano da pesquisa, restarem em situações tão diferenciadas, conforme exposto linhas acima (Quadro 1). Seguindo a estratégia analítica estruturada, focada nos percursos institucionais subjacentes à conformação operacional dos agentes que estabelecem processos interativos,buscamos recuperar o histórico de construção institucional de cada órgão, investigando os elementos que estariam associados ao desenvolvimento dessas capacidades nos seus entremeios, ponderando por temática de trabalho e inserção executivo-operacional.

\subsection{O histórico de desenvolvimento do MDS}

O Ministério do Desenvolvimento Social e Combate à Fome (MDS) surgiu no ano de 2004, no início do primeiro governo Lula. Sua conformação se deu a partir de um movimento muito mais amplo de institucionalização da política de assistência social no Brasil, recrudescido, pode-se dizer, a partir da promulgação da Constituição de 1988, em particular tendo por base movimentos de normatização da seara ocorridos mais fortemente a partir dos anos 2000 (Cunha, 2011). O órgão passa por transformações importantes ao longo do tempo.

A proporção de técnicos envolvidos que, muito embora não pertencentes a uma carreira específica do órgão, logravam trabalhar numa carreira especializada na temática, saltou de aproximadamente 8\% em 2008 para quase 35\% em 2012, por exemplo (CGU, s.d.). Além disso, o órgão foi capaz de, ao final da década, compor uma carreira própria no âmbito da administração pública (Vaz, 2016). Outro aspecto que merece destaque concerne às interfaces socioestatais utilizadas pelo MDS no âmbito da gestão de seus programas. Em 2004, por exemplo, nenhum programa ainda havia sido submetido a Audiências Públicas ou mesmo Consultas Públicas. Já em 2009, a proporção daqueles que se utilizavam de ambas as interfaces era de, em média, 48\% do total daqueles em execução (Pires; Vaz, 2014).

$\mathrm{O}$ que podemos dizer do MDS, em suma, é que consiste num órgão que chancela e institucionaliza um movimento muito mais amplo e participativo de concretização da política de assistência social no Brasil, especialmente a partir de 1988. O caráter societal do órgão parece ter sido determinante de suas próprias estruturas institucionais, especialmente quando a pensamos desde o ponto de vista da capacidade de formulação de políticas públicas para a área. Assim, podemos dizer que a própria conjuntura de criação do MDS se embasou numa movimentação ulterior da sociedade nos entremeios da área de assistência social.

\subsection{O histórico de desenvolvimento do MEC}

O Ministério da Educação (MEC) tem origem em 1930, sob a nomenclatura de Ministério dos Negócios da Educação e da Saúde Pública, tendo por base a gestão e administração de todos os assuntos relacionados não só ao ensino, mas, também, à saúde pública e à gestão hospitalar. A criação do órgão nesse momento estava circunscrita num movimento mais amplo de institucionalização da política de educação no país (Vidal, 2003), reforçado especialmente com os debates em torno da criação da primeira Lei de 
Diretrizes e bases da Educação (LDB). O fim do regime militar, em 1985, marca a estruturação do Ministério da Educação e, no início da década de 1990, dois fatores marcam a atuação do MEC na área: a institucionalização da Política Nacional de Educação (PNE) e a reformulação da LDB.

A PNE foi estabelecida pela Constituição de 1988, tendo sido fruto da atuação de movimentos de profissionais e grupos de base em torno da temática. A militância desses agentes foi fundamental para aprovação do Plano e sua consolidação no âmbito da promulgação da Carta Magna. Além disso, essa própria militância também foi fundamental na composição das discussões da nova LDB - que, promulgada em 1996, previa, por exemplo, maior autonomia aos entes federados na gestão de políticas públicas na área educacional, dentre outros elementos. Pode-se dizer que o órgão vem se especializando e capacitando cada vez mais, técnica e politicamente, para conseguir lograr a disposição dessas tarefas.

Pelo menos desde meados da década de 1990, o MEC tem sido capaz de realizar concursos públicos próprios, aglutinar um conjunto de técnicos de carreiras próprias e, por fim, dispensar o recurso humano não ligado à sua temática de trabalho (IPEA, 2012). Além desse fator, vale a pena notar também que o órgão tem sido capaz de recrudescer a utilização de interfaces socioestatais, tendo em 2004, por exemplo, apenas 12,3\% dos seus programas escrutinizados em Conferências Temáticas da área, percentual que já era de quase 73\% em 2009 (PIRES;VAZ, 2012). Assim, de uma maneira geral, podemos dizer que o MEC vem se consolidando com base em movimentos de profissionais e da sociedade que se constituem verdadeiras militâncias em torno da temática da educação.

\subsection{O histórico de desenvolvimento do MINA}

O Ministério da integração Nacional (MINA) teve por primórdios institucionais, pode-se dizer, a criação, em 1891, do chamado Ministério da Justiça e Negócios Interiores. As principais competências atribuídas ao novo órgão concerniam aos serviços e negócios relativos à administração da justiça local e à administração federal, bem como, dentre outros, a tudo que fosse concernente ao desenvolvimento das ciências, letras e artes. Em 1967, o Ministério é desmembrado através do Decreto-Lei 200, repercutindo na criação do chamado Ministério do Interior, que passa a gerir e administrar agências de importância seminal para o desenvolvimento brasileiro, como a SUDENE (Superintendência de Desenvolvimento do NE).

Em 1990, o Ministério é extinto, criando-se, dentre a estrutura da Presidência da República, a chamada Secretaria de Desenvolvimento Regional, abrangendo outras Superintendências, como a do Desenvolvimento da Zona Franca de Manaus e a Empresa Brasileira de Turismo. Em 1992, a Secretaria é transformada novamente em Ministério, culminando na criação do Ministério da Integração Nacional. Já em 1995, com os dispositivos da reforma gerencial estatal brasileira (Cardoso Jr., 2012), o Ministério é mais uma vez extinto, criando-se outra Secretaria para a temática: a Secretaria Especial de Políticas Regionais, que fica subordinada, desta feita, ao Ministério do Planejamento e Orçamento. 
Subsequentemente, em 1999, o Ministério da Integração Nacional foi recriado, tendo aprovada sua estrutura regimental apenas sete anos depois, no ano de 2006.

$\mathrm{O}$ que podemos perceber com esse histórico de criação do Ministério é a existência de significativa inconstância na atribuição de funções e institucionalidades. O formato atual assumido pelo órgão é relativamente recente e seu histórico é, no mínimo, confuso: ora o Ministério é transformado numa Secretaria, ora volta a ter status de Ministério; ora engloba funções e autarquias, ora essas responsabilidades são extintas. Essa miscelânea institucional parece ter reflexos claros nas suas capacidades burocráticas e políticas, sendo que, ao longo dos anos 2000, o Ministério não apenas foi incapaz de abrir novos concursos e fortalecer carreiras próprias, como, também, vem perdendo sistematicamente técnicos capacitados na sua temática de trabalho (Vaz, 2016). Ademais, não existem evidências acerca do envolvimento da sociedade ou profissionais afetos à temática na constituição do órgão.

\subsection{O histórico de desenvolvimento do ME}

A história institucional do esporte no Brasil teve início em 1937, com a criação da Divisão de Educação Física do Ministério da Educação e Cultura. Em 1970, a divisão foi transformada em Departamento de Educação Física e Desportos, ainda vinculada a esse Ministério. Na seqüência, em 1978, o Departamento foi transformado em Secretaria de Educação Física e Desporto, permanecendo assim até 1989. Em 1990, extingue-se essa Secretaria, sendo criada a Secretaria de Desportos na estrutura da Presidência da República. Já em 1992, essa Secretaria passa a ser vinculado ao Ministério da Educação. A partir de 1995, cria-se o Ministério Extraordinário do Esporte, cabendo à Secretaria de Desportos, ainda vinculada ao Ministério da Educação, prestar-lhe apoio técnico e administrativo.

Em março do mesmo ano, esta secretaria é transformada no Instituto Nacional de Desenvolvimento do Desporto (INDESP), sendo desvinculado do MEC e passando a se subordinar ao Ministério Extraordinário do Esporte. Em 1998 é criado o Ministério do Esporte e Turismo, sendo que o INDESP passa a ser vinculado a este órgão. Em outubro de 2000, o INDESP é extinto e substituído pela Secretaria Nacional de Esporte. Em 2003, as duas pastas, Esporte e Turismo, são separadas, ficando, cada qual, com um Ministério próprio.

O histórico de criação do Ministério do Esporte envolve, vale dizer, em pouca medida a participação e/ou a militância de movimentos sociais e da sociedade de uma forma geral. Nesse aspecto, o processo se caracteriza com bastante similaridade àquele concretizado no caso do Ministério da Integração Nacional. A pasta de esporte ora tomou a forma de uma Secretaria, ora tomou a forma de um Ministério, ainda que, no geral, em conjunto com outras temáticas. A existência de um Ministério próprio é relativamente recente, sendo que seu percurso institucional pouco envolveu instâncias e/ou movimentos advindos da sociedade.

\subsection{Analisando comparativamente os Órgãos}

A análise do desenvolvimento histórico dos órgãos nos fornece algumas dicas acerca do potencial de desenvolvimento de capacidades políticas e burocráticas (Quadro 4). 
Quadro 4 - Parâmetros de avaliação dos Órgãos elencados para análise

\begin{tabular}{|c|c|c|c|}
\hline & Corporativo & Societal & Normativo \\
\hline MDS & $\begin{array}{l}\text { Criação de carreira pró- } \\
\text { pria, realização de con- } \\
\text { cursos públicos e capa- } \\
\text { citação de servidores }\end{array}$ & $\begin{array}{l}\text { Movimentos sociais e } \\
\text { militantes na área, con- } \\
\text { duzindo a formação das } \\
\text { políticas e estruturações } \\
\text { normativas; uso intensivo } \\
\text { de interfaces socioestatais }\end{array}$ & $\begin{array}{l}\text { Desenvolvimento nor- } \\
\text { mativo com previsão } \\
\text { Constitucional de forta- } \\
\text { lecimento da área como } \\
\text { política pública, com } \\
\text { foco nas relações com os } \\
\text { atores sociais envolvidos }\end{array}$ \\
\hline MEC & $\begin{array}{l}\text { Fortalecimento das car- } \\
\text { reiras próprias, realização } \\
\text { de vários concursos e } \\
\text { capacitação de servidores }\end{array}$ & $\begin{array}{l}\text { Movimentos da sociedade } \\
\text { de conformação das nor- } \\
\text { mativas das áreas, como } \\
\text { especialistas, Academia e } \\
\text { entidades afins; uso intensivo } \\
\text { de interfaces socioestatais }\end{array}$ & $\begin{array}{l}\text { Estabelecimento de } \\
\text { planos de fortalecimento } \\
\text { da área como política } \\
\text { pública, especialmen- } \\
\text { te com a descentrali- } \\
\text { zação administrativa } \\
\text { e relações constantes } \\
\text { com atores sociais }\end{array}$ \\
\hline MINA & $\begin{array}{l}\text { Carreiras próprias descen- } \\
\text { tralizadas nas Autarquias, } \\
\text { sem uma única carrei- } \\
\text { ra centralizadora, capaz } \\
\text { de fornecer um senso } \\
\text { de missão institucional. } \\
\text { Realização precárias de } \\
\text { concursos públicos }\end{array}$ & $\begin{array}{l}\text { Pouca existência de re- } \\
\text { lações com movimentos } \\
\text { da sociedade, geralmente } \\
\text { centradas em grupos espe- } \\
\text { cíficos já ligados à temática }\end{array}$ & $\begin{array}{l}\text { Desenvolvimento pouco } \\
\text { linear institucional como } \\
\text { foco de especificidade e } \\
\text { objetividade das próprias } \\
\text { políticas da área, sem } \\
\text { foco específico nas rela- } \\
\text { ções com atores sociais } \\
\text { de maneira ampliada }\end{array}$ \\
\hline $\mathrm{ME}$ & $\begin{array}{l}\text { Carreira própria ine- } \\
\text { xistente, contando com } \\
\text { carreiras de outros Órgãos; } \\
\text { planos de capacitação } \\
\text { inexistentes; Concur- } \\
\text { sos públicos precários. }\end{array}$ & $\begin{array}{l}\text { Existência precárias de } \\
\text { movimentos anteriores, } \\
\text { geralmente centrados em } \\
\text { Ligas e/ou entidades de } \\
\text { modalidades específicas }\end{array}$ & $\begin{array}{l}\text { Desenvolvimento pouco } \\
\text { linear institucional como } \\
\text { foco de especificidade e } \\
\text { objetividade das próprias } \\
\text { políticas da área, sem } \\
\text { foco específico nas rela- } \\
\text { ções com atores sociais } \\
\text { de maneira ampliada }\end{array}$ \\
\hline
\end{tabular}

Fonte: elaboração própria, 2014.

Em primeiro lugar, se tomarmos por base o parâmetro de desenvolvimento institucional, não é difícil notar a relação entre os percursos históricos traçados por cada qual e a situação atual em que se encontram em termos de capacidade burocrática. O MDS e o MEC vêm fortalecendo suas respectivas capacidades através da constituição de um corpo técnico próprio e, principalmente, afeto à suas respectivas missões institucionais. Em termos de desenvolvimento corporativo, isso implica a constituição de um corpo técnico-burocrático forte, disciplinado e efetivamente identificado com as atividades e operações de cada órgão. 
Já no caso do MINA e do ME, parece que o desenvolvimento institucional pouco linear de ambos teve por principal consequência o contrário disso, isto é, a falta de identidade burocrática de maneira geral. A maioria dos técnicos que trabalham nesses órgão são lotados através de requisições (Vaz, 2016). Ademais, as carreiras próprias de cada qual, quando existentes, são pouco fomentadas e valorizadas, seja através da realização de concursos públicos, seja através da efetiva concentração de suas atividades em áreas realmente afetas à temática geral com a qual lidam.

A análise do parâmetro societal também aponta diferenças significativas entre os órgãos estudados. Quando analisamos os casos do ME e MINA, por exemplo, observamos que o percurso institucional centralizado e relativamente fechado que resultou na criação de ambos parece ter condicionado suas respectivas capacidades de baixo desenvolvimento político. A seu turno, para MDS e MEC, notamos situação contrária: sua criação esteve ligada muito mais à institucionalização de movimentos já presentes na sociedade em prol da certificação e concretização de políticas públicas nas suas respectivas áreas. Isso resultou na capacidade de apresentar melhores resultados tanto em termos burocráticos, quanto políticos. Assim, atualmente, ao passo que MDS e MEC vem fazendo uso significativo de diversas interfaces socioestatais para a gestão de seus programas, MINA e ME parecem caminhar na direção contrária, de baixa utilização dessas instâncias para a gestão de seus respectivos programas e políticas.

O último parâmetro que importa analisar concerne ao aspecto normativo. $\mathrm{O}$ caso do MDS e do MEC, por exemplo, é singular nesse sentido, porque ambos contam, na própria Carta Constitucional, com a previsão de criação de Conselhos Gestores de Políticas nos três níveis de governo como condição para gestão e repasse de recursos (Avritzer, 2009). Essa previsão, pode-se dizer, tende a moldar a própria atuação dos técnicos e gestores do campo na direção de se preocuparem muito mais com a negociação e aprovação de ações e políticas pela sociedade do que áreas nas quais tais previsões legais são inexistentes (Cunha, 2011).

No caso do MINA e do ME, temos situação relativamente diferente. As legislações que regulamentaram ambas as áreas contam, de maneira muito restrita, com a previsão de desenvolvimento de políticas através da negociação com a sociedade e, mesmo no caso em que o fazem,elas parecem originadas muito maisda emulação de outras áreas técnicas do que em função de movimentos sociais prévios e ulteriores de base de suas próprias áreas de atuação. Esse fato ajuda a explicar as razões pelas quais as legislações participativas nessas áreas são muito menos desenvolvidas e estruturadas do que as legislações das áreas do MDS e do MEC, por exemplo.

Em suma, podemos dizer que, factualmente, os órgãos aqui analisados diferem sobremaneira no seus respectivos desenvolvimentos histórico-institucionais, seja em termos de conformação de um corpo burocrático consistente, seja na conformação de capacidades políticas fortes. O que importa concluir a partir dessa comparação é que a situação atual de gestão de cada qual, bem como suas perspectivas futuras de desenvolvimento institucional e da própria área, são, em grande medida, repercussões desses processos históricos de estruturação. A existência de movimentos da sociedade afetos e militantes nas áreas e a 
conformação institucional dessas políticas pode levar a uma situação de melhores capacidades políticas e burocráticas. Esses são fatores que concorrem para um desenvolvimento institucional de caráter mais linear e sistematizado, bem como para um corpo burocrático capaz de gerir as políticas de maneira mais voltada aos atores sociais de uma maneira geral.

\section{Cotejando capacidades e resultados em políticas públicas}

Para além da importância dessas constatações, o que a discussão apresentada nos leva a questionar é: em que sentido e/ou medida esses fatores repercutem no trabalho desses órgãos? A literatura já vem apontando dada relação entre instituições com maiores capacidades e aqueles com maiores proporções de programas cujos resultados são passíveis de serem considerados satisfatórios (Pires; Gomide, 2016;Vaz, 2016). Essa tendência nos sugere fortemente a necessidade de investigação pouco mais profunda dos programas desenvolvidos nos seus entremeios. Para tanto, tecemos considerações do desenvolvimento de cada programa elegido para análise, seguindo as especificações analítico-metodológicas definidas para o estudo.

\subsection{O Programa de Erradicação do Trabalho Infantil (PETI/MDS)}

Foi criado com objetivo de retirar crianças e adolescentes do trabalho que coloca em risco sua saúde e segurança. A atuação do Programa consiste no recebimento de uma bolsa mensal por cada indivíduo retirado do trabalho. O programa é financiado com recursos do Fundo Nacional de Assistência Social e co-financiamento dos estados e municípios, podendo ainda contar com a participação financeira da iniciativa privada e de sociedade civil.

A gestão do programa conta com diversos atores envolvidos, dentre governos federal, estadual e municipal, além de instâncias de controle social cuja composição se dá tanto com membros do Estado, quanto com membros da sociedade. Uma vez implementado, sua administração no âmbito municipal é realizada pela chamada Comissão Municipal de Erradicação do Trabalho Infantil, sendo seu trabalho referendado pelo Conselho $\mathrm{Mu}$ nicipal de Assistência Social. No que tange ao alcance de resultados, o PETI apresentou cumprimento de mais de $80 \%$ de suas metas na maior parte do tempoem que foi executado (Pires;Vaz, 2014). Na percepção de um dos gestores, pelo menos duas seriam suas principais características.

Primeiro, a transversalidade institucional, focada justamente na existência de arenas híbridas, compostas por Estado e sociedade, como seu principal fator de sucesso. A segunda característica faria referência ao escopo de execução no âmbito municipal. Em geral, municípios de menor porte, que são justamente aqueles nos quais são encontradas com maior frequência as situações de trabalho infantil, não teriam uma estrutura burocrática consolidada e forte. As dificuldades decorreriam do desconhecimento da temática por parte dos gestores locais, bem como da falta de comprometimento com prazos de prestação de contas e de elaboração de relatórios técnicos de progresso. Além disso, foi relatada muita rotatividade nas equipes locais. 


\subsection{O Programa Brasil Alfabetizado (PBA/MEC)}

Criado em 2003, tem por objetivo a erradicação do analfabetismo, consistindo no apoio técnico a municípios na estruturação de módulos de estudo continuado para indivíduos de 15 anos ou mais de idade. No âmbito municipal, o governo conta com a atuação do Conselho Municipal de Educação para o acompanhamento da execução financeira do Programa, bem como, em especial, da fiscalização efetiva dos recursos. A organização do programa segue um esquema que, a priori, não envolve grandes complexidades para a execução, mas depende da adesão voluntária dos atores governamentais para sua realização.

Os resultados apresentados têm sido satisfatórios ao longo do tempo, sendo que, por exemplo, sua taxa de cobertura aumentou significativamente na década de 2000, passando de 1.667 para mais de 3.300 municípios entre 2004 e 2009 (IPEA, 2012). Essa capacidade de diversificação e aumento quantitativo do Programa pode ser atribuída à capacidade dos atores envolvidos de efetivamente manterem canais de contato significativos entre si. A entrevista com o gestor do Programa deixou claro pelo menos dois importantes aspectos.

Em primeiro lugar, o fato de o MEC estabelecer contatos diretos, através de convênios, com municípios e/ou entidades assistenciais interessadas na execução do Programa. De fato, a possibilidade de negociar e interagir diretamente com os atores implementadores do Programa foi dada como elemento de relevância para sua efetiva concretização e execução. Em segundo lugar, a existência de capacidade de fiscalização efetiva da execução dos recursos no âmbito municipal. Foi possível, por exemplo, disponibilizar pessoal para realização de visitas técnicas aos municípios nos quais o Programa estava sendo executado e observar de perto as atividades empreendidas. Além disso, esse potencial de fiscalização era ampliado em função das parcerias que eram estabelecidas com os Conselhos Municipais de Educação.

\subsection{O Programa Segundo Tempo (PST/ME)}

Foi instituído em 2003 com objetivo de prover acesso à prática e à cultura do esporte para crianças e adolescentes. $\mathrm{O}$ arranjo institucional concebido para inter-relacionamento entre os agentes executores do PST se conforma pela elaboração de acordos técnicos de cooperação entre o governo federal diretamente com as administrações municipais, em especial com as escolas públicas. $\mathrm{O}$ processo de pactuação pressupõe a presença do Conselho Municipal do Esporte como instância fiscalizadora da aplicação dos recursos transferidos ao programa. Na visão do gestor entrevistado, pelo menos quatro grandes problemáticas estavam atreladas ao Programa.

Em primeiro lugar, a equipe do próprio ME não era de fato especializada na área, mas, sim, na gestão orçamentária do Programa. Essa falta de conhecimento do assunto levou a entraves na fiscalização efetiva das atividades, porque o Ministério não dispunha de uma rede de fiscalização efetiva para além do cumprimento das ações de execução orçamentária. A segunda problemática estava ligada às negociações que envolviam o repasse 
dos recursos, especialmente no tocante à forma de descentralização dos mesmos através de acordos técnicos de cooperação. Esses acordos poderiam ser realizados de maneira direta com os agentes executores, mas, via de regra, não estavam atrelados a planilhas de referência em termos de preço de produtos e serviços.

A terceira questão concernia à fiscalização efetiva das atividades desempenhadas. $\mathrm{O}$ Ministério, como dito, não dispunha de especialistas na área dentre o quadro de gestores do Programa. A quarta e última problemática apontada concerne aos processos de prestação de contas do Programa. Como não haviam equipes de fiscalização, as prestações eram postergadas, ou às vezes nem mesmo realizadas.

\subsection{O Programa Desenvolvimento Agricultura Irrigada (PDAI/MINA)}

Foi criado no ano de 2003, tendo por objetivo o financiamento da implantação, capitalização e agilização burocrático-processual no licenciamento e outorga de projetos de irrigação. Sua operação consiste na transferência de recursos diretamente a entidades rurais que fazem intermédio de financiamento de projetos da agricultura familiar. É gerido de maneira descentralizada, tendo por foco o governo federal e entidades escolhidas pelo próprio governo para serem beneficiários das ações. Três problemáticas foram dadas como significativos entraves aoprograma na entrevista realizada.

O primeiro entrave tem relação com a situação de gestão dentro da própria administração federal. Segundo o entrevistado, existe uma alta rotatividade de servidores levando à falta de continuidade na execução do programa. O segundo entrave concerne à descentralização administrativa. Atividades rotineiras na gestão, como a consolidação de processos orçamentários, ou, ainda, a confecção de planos de trabalho, são realizadas por equipes diferentes, inexistindouma sistemática de centralização e padronização dessas ações. Por fim, o último grande entrave tange à falta de consulta e diálogo com outros agentes afetados pelas atividades e ações desenroladas no âmbito do programa.

Via de regra, existe, segundo o entrevistado, uma diretiva comum dentre as equipes gestoras de composição, elas próprias, de grupos e comunidades rurais para repasse dos recursos. Os municípios geralmente não são consultados acerca dos objetivos traçados para o seu território. Nessa mesma linha, não há diretriz para a prestação de contas e/ou mesmo a realização de acordos com Conselhos Gestores locais para a publicização de ações e resultados. As reuniões são realizadas, na verdade, apenas com os beneficiários do Programa.

\subsection{Análise comparativa dos Programas}

A análise dos Programas revelou importantes aspectos e dicas no que toca à relação entre capacidades burocráticas e políticas dos órgãos e resultados apresentados em termos de políticas públicas. Tanto o histórico dos programas, quanto a percepção dos gestores, foram elementos essenciais nesse sentido, principalmente quando tomamos por base os aspectos analíticos sugeridos para essa parte do estudo (Quadro 5). Os resultados sugerem existir, de fato, alguma relação entre as capacidades dos órgãos executores e os resultados apresentados em termos de políticas públicas específicas. 
Quando analisamos o primeiro parâmetro, Objetivos e Resultados, observamos que, na percepção de seus respectivos gestores, os programas desenvolvidos por MDS e MEC obtiveram alcance satisfatório de resultados, ao passo que aqueles desenvolvidos por $\mathrm{ME}$ e MINA obtiveram resultados muito abaixo do esperado. Pelo menos essa variável já tende a condizer com a análise anterior que nos mostrou que o desenvolvimento institucional de MDS e MEC foi muito mais linear e consistente do que dos outros dois órgãos, levando-os a potencializar melhor capacidades burocráticas e políticas.

Isso fica evidente no próximo parâmetro que é o de Recursos e Estratégias. Nesse caso, tanto para MDS, quanto para o MEC, os gestores afirmaram que os respectivos corpos técnicos eram adequados para o trabalho. E essa adequação se dava seja no conhecimento que os trabalhadores detinham da temática, seja na própria disponibilidade dos órgãos de criação de carreiras próprias para suas respectivas gestões. Esse movimento, vale dizer, não foi observado para os casos de MINA e ME, o que se refletiu nos seus prognósticos nesse caso, já que os gestores afirmaram, via de regra, que o corpo técnico não era afeto à área de trabalho e, geralmente, era cedido por outros órgãos.

Quadro 5 - Avaliação dos Programas elencados para análise, segundo percepção dos entrevistados

\begin{tabular}{|c|c|c|c|}
\hline \multicolumn{5}{|c|}{$\begin{array}{c}\text { Objetivos } \\
\text { e Resul- } \\
\text { tados }\end{array}$} & $\begin{array}{c}\text { Recursos e } \\
\text { Estratégias }\end{array}$ & $\begin{array}{c}\text { Negociação e Im- } \\
\text { plementação }\end{array}$ & Abertura e Acesso \\
$\begin{array}{c}\text { Alcance } \\
\text { satisfa- } \\
\text { tório de } \\
\text { resultados }\end{array}$ & $\begin{array}{c}\text { Corpo téc- } \\
\text { nico afeto à } \\
\text { área, inclusi- } \\
\text { ve contando } \\
\text { com carreiras } \\
\text { próprias }\end{array}$ & $\begin{array}{c}\text { Definição clara de papéis } \\
\text { e objetivos dos atores } \\
\text { ao longo do processo, } \\
\text { sem mudanças bruscas } \\
\text { na operacionalização }\end{array}$ & $\begin{array}{c}\text { Estratégia clara de in- } \\
\text { teração com conselhos } \\
\text { e órgãos participativos } \\
\text { territoriais, especialmen- } \\
\text { te para implementação }\end{array}$ \\
$\begin{array}{c}\text { Alcance } \\
\text { satisfa- } \\
\text { tório de } \\
\text { resultados }\end{array}$ & $\begin{array}{c}\text { Corpo téc- } \\
\text { nico afeto à } \\
\text { área, inclusi- } \\
\text { ve contando } \\
\text { com carreiras } \\
\text { próprias }\end{array}$ & $\begin{array}{c}\text { Definição clara de papéis } \\
\text { e objetivos dos atores } \\
\text { ao longo do processo, } \\
\text { sem mudanças bruscas } \\
\text { na operacionalização }\end{array}$ & $\begin{array}{c}\text { Estratégia clara de in- } \\
\text { teração com conselhos } \\
\text { e órgãos participativos } \\
\text { territoriais, especial- } \\
\text { mente para fiscalização }\end{array}$ \\
$\begin{array}{c}\text { Alcance } \\
\text { de resulta- } \\
\text { dos muito } \\
\text { abaixo do } \\
\text { esperado }\end{array}$ & $\begin{array}{c}\text { Corpo téc- } \\
\text { nico, via de } \\
\text { regra, não } \\
\text { afeto à área } \\
\text { e cedido por } \\
\text { outros órgãos }\end{array}$ & $\begin{array}{c}\text { Técnicos atuando, em } \\
\text { geral, de maneira autô- } \\
\text { noma com cada agente } \\
\text { de convênio, sem inter- } \\
\text { locução mútua, variando } \\
\text { muito o seu desenho } \\
\text { de implementação }\end{array}$ & $\begin{array}{c}\text { Pouca ou nenhuma } \\
\text { interação com institui- } \\
\text { çarticipativas locais, } \\
\text { atuando diretamente } \\
\text { com os convenentes, } \\
\text { seja para implementação, } \\
\text { seja para fiscalização }\end{array}$ \\
\hline
\end{tabular}




\begin{tabular}{|c|c|c|c|c|}
\hline $\begin{array}{l}\text { PAI/ } \\
\text { MINA }\end{array}$ & $\begin{array}{l}\text { Alcance } \\
\text { de resulta- } \\
\text { dos muito } \\
\text { abaixo do } \\
\text { esperado }\end{array}$ & $\begin{array}{l}\text { Corpo téc- } \\
\text { nico, via de } \\
\text { regra, não } \\
\text { afeto à área } \\
\text { e cedido por } \\
\text { outros órgãos }\end{array}$ & $\begin{array}{l}\text { Atuação direta com famí- } \\
\text { lias pode ter gerado situa- } \\
\text { ção de pouca interlocução } \\
\text { entre os demais agentes } \\
\text { do plano, com bastante } \\
\text { variabilidade no seu de- } \\
\text { senho de implementação }\end{array}$ & $\begin{array}{l}\text { Pouca ou nenhuma } \\
\text { interação com institui- } \\
\text { ções participativas locais, } \\
\text { atuando diretamente } \\
\text { com os convenentes, } \\
\text { seja para implementação, } \\
\text { seja para fiscalização }\end{array}$ \\
\hline
\end{tabular}

Fonte: entrevistas com gestores dos programas, 2014.

O penúltimo parâmetro de análise concerne ao de Negociação e Implementação. Nesse caso, gestores do MDS e MEC afirmaram, em geral, que os papéis dos atores estavam bem definidos no âmbito dos projetos, assim como não houveram mudanças bruscas nesses papéis no momento da implementação desses projetos. Isso garantiu continuidade e segurança institucional para os trabalhos de todos os agentes envolvidos. Já no caso de MINA e ME, parece que situação contrária se estabeleceu: a interlocução entre os agentes era muito rara, bem como a atuação bastante individualizada, em função do desenho dos programas.

Isso fez com que cada agente atuasse de uma maneira específica e, em alguns casos, fosse possível observar mudanças bruscas na implementação definidas por atores específicos, mas que não tinham uma fiscalização efetiva central. Implica que o programa pode ter sido implementado de diversas formas, nos diferentes lugares, sem que os próprios agentes institucionais dialogassem entre si, ou mesmo com o centro de implementação. Por fim, último parâmetro se refere à Abertura e Acesso e, nesse caso, MDS e MEC tiveram, na percepção dos gestores, importante interação com instituições participativas territoriais, em especial os Conselhos Gestores Municipais. Já no caso de ME e MINA, parece que esse contato foi bem menor e/ou mesmo inexistente, seja para fins de implementação, seja para fins de fiscalização.

\section{3. À guisa de conclusão}

O que podemos afirmar, enfim, da relação entre capacidades políticas e burocráticas a partir da análise dos casos estudados? Pelo menos duas grandes conclusões podem ser realizadas. Em primeiro lugar, a comparação entre os órgãos revelou diferenças importantes acerca dessas capacidades no tocante a cada um deles. O MDS e o MEC são aqueles com maiores potencialidades nesse sentido, ao passo que o ME e MINA são aqueles com menores potencialidades na escala. A explicação dessa diferença parece residir no próprio histórico de desenvolvimento desses órgãos. Tanto o MDS, quanto o MEC, tenderam a, na verdade, consolidar todo um movimento ulterior de mobilização da sociedade e dos profissionais em torno de políticas das áreas sobre as quais versam cada qual.

Essa perspectiva de trajetória e consolidação institucional parece estar muito menos presente no caso tanto do ME quanto do MINA. Em ambos os casos, o que observamos claramente é um padrão institucional muito mais cambiável e caótico do que um padrão 
de sistemática de concretização institucional. Os dois Ministérios foram fundados no início do governo Lula, por volta do ano de 2003, após sofrerem diversos tipos de mutações institucionais desde a promulgação da Constituição. Eles já assumiram o papel de Secretaria de outros Ministérios, Secretaria Extraordinário, Departamentos, Superintendências e, por fim, foram finalmente chancelados como Ministérios. Essa diversificação espelha não apenas a quase inexistência de movimentos da sociedade em torno da área, tal como nos casos anteriores, mas, também, tende a dificultar a consolidação efetiva de um corpo burocrático capaz, inclusive, de estabelecer relações efetivas com a sociedade através da adoção de interfaces socioestatais.

A segunda consideração a ser feita concerne aos resultados apresentados por cada órgão, sendo que cada um conta, como visto, com Programas com desenhos institucionais muito específicos, que tendem a considerar em diferentes graus o contato, por exemplo, com interfaces socioestatais. No caso do MDS e MEC, esse desenho privilegia a negociação com diversos órgãos de controle social, como Conselhos Gestores, bem como com os governos envolvidos na gestão. Dessa forma, atividades como a fiscalização do cumprimento efetivo das atividades acordadas tende a ser desempenhada de maneira conjunta e pactuada, muito embora esse modelo também enfrente uma série de dificuldades, como visto. Ainda assim, sua efetivação parece favorecer a divisão do trabalho entre os agentes num claro sistema de parceria, no qual as informações são efetivamente trocadas e os ajustes necessários são realizados de maneira concisa.

Já no caso dos Programas avaliados para o MINA e o ME, observamos desenhos que privilegiam uma gestão de caráter muito mais top-down. É singular, por exemplo, o Programa de Agricultura Irrigada, que sequer tende a estabelecer negociações claras e/ou mesmo diretas com os Estados e municípios para efetivação de suas ações. Nesse mesmo sentido, o Programa Segundo Tempo tende a estabelecer parcerias com um número limitado de agentes, ficando impossibilitado, inclusive, de proceder as fiscalizações efetivas das atividades porque não é capaz de atuar numa lógica de parceria com instituições como Conselhos Gestores, dentre outros.

Combinadas, essas duas conclusões parecem confirmar/demonstrar a hipótese de que, de fato, Programas que tendem a estabelecer e qualificar suas parcerias, tendem a apresentar melhores resultados no tocante à sua gestão e efetivação no plano local. Dessa forma, não é dificil imaginar a razão que faz com que o desenvolvimento de capacidades políticas e burocráticas seja uma questão de seminal importância para instituições governamentais no cenário atual.

\section{Referências}

ALBUQUERQUE, Eduardo da Motta e . Agenda Rosdolsky. 1. ed. Belo Horizonte: Editora UFMG, 2013.

AVRITZER, Leonardo. Entre o conflito de interesses e a nova institucionalidade política. Novos Estudos CEBRAP (Impresso), v. 103, p. 211-217, 2015. 
BARRETO, Rafael ; VAZ, Alexander Cambraia N. ; JANNUZZI, Paulo de Martino . Capacidade de Gestão de Políticas Sociais. Revista Brasileira de Monitoramento e Avaliação, v. 3, p. 112-135, 2012.

BOBBIO, Norberto. Estado, governo, sociedade - para uma teoria geral da política. 10. ed. Tradução Marco Aurélio Nogueira. São Paulo: Paz e Terra, 2003.

BOSCHI, Renato R; GAITÁN, Francisco. Intervencionismo Estatal e Políticas de Desenvolvimento na América Latina. Caderno CRH, v. 21, n. 53, p. 303-319, 2009.

BRESSER-PEREIRA, Luis Carlos. From the national-bourgeoisie to the dependency interpretation of Latin America (LAP). Latin American Perspectives, v. 38, 2011.

Um Estado novo-desenvolvimentista na América Latina? Economia e sociedade, v. 21, número especial, 2013.

CARDOSO JR, José C. Planejamento governamental e gestão pública no Brasil: elementos para ressignificar o debate e capacitar o Estado. Texto para Discussão 1584, IPEA, 2012.

Controladoria-Geral da União (CGU) Banco de dados dos servidores da administração pública federal. s.d Disponível em: <www.portaldatransparencia.gov.br>. Acesso em: 10 maio 2014.

CHANG, Han-Jong. The political economy of industrial policy. New York: Palgrave Macmillan, 1995.

Globalization, economic development and the role of the state. London: Zed Books, 2003.

COELHO,Vera Schatan R.P.; NOBRE, Marcos (Org.). Participação e Deliberação:Teoria Democrática e Experiências Institucionais no Brasil Contemporâneo. São Paulo: Editora 34, 2004.

CUNHA, Eleonora S. M. Inclusão Social e Política: o desafio deliberativo dos Conselhos Municipais de Assistência Social. In: AVRITZER, Leonardo (Org.). A Dinâmica da Participação Local no Brasil. São Paulo: Cortez, 2011.

EDIGHEJI, Omano. Constructing a democratic developmental state in South Africa. Constructing the 21st century developmental State. Cidade do Cabo: HSRC Press, 2010.

EVANS, Peter. Building bridges across a double divide: aliances between US and Latin American labor and NGOS. Development in Practice, v.14,n. 1-2, p. 34-47, 2004.

Embedded autonomy : States and industrial transformation. New Jersey: Princeton Press, 1995.

O Estado como problema e solução. Lua Nova, n. 28-29, abr. 1992.

The capability enhancing developmental state: concepts and national trajectories. Niterói: Cede, Texto para Discussão, n. 63, 2011.

.; RAUCH, James. Bureaucracy and growth: a cross-national analysis of the effects of "Weberian" State. American sociological review, v. 64, n. 5, 2000.

.; RUESCHEMEYER, Dietrich; SKOCPOL, Theda. Bringing the State back in. Cambridge: University Press, 1985

FURTADO, Celso. O mito do desenvolvimento econômico. Rio de Janeiro: Paz e Terra, 1998.

HENDRIX, Charles S. Measuring state capacity: theoretical and empirical implications for the study of civil conflict. Journal of Peace Research, 2010.

HOWletT, Michael; RAMeSH, M.. Studying Public Policy: Policy Cycles and Policy Subsystems. Oxford: University Press, 2003.

IPEA. Brasil em Desenvolvimento 2011: Estado, Planejamento e Políticas Públicas. v. 1. Brasília, IPEA: 2012,

JOHNSON, Carl A. The developmental state: odyssey of a concept. In:WOO-CUMINGS, M. The developmental state. Ithaca: Cornell University Press, 1995.

The industrial policy debate. Califórnia: ICS Press, 1984.

LAVAlle, Adrian Gurza; HOUTZAGER, Peter; CASTELlO, Gabriela. Democracia, pluralização da representação e sociedade civil. Lua Nova, São Paulo, n. 67, p. 49-103, 2006. 
.; SZWAKO, JOSÉ. Sociedade civil, Estado e autonomia: argumentos, contra-argumentos e avanços no debate. Opinião Pública, v. 21, p. 157-187, 2015.

LEFTWICH,Adrian. Bringing politics back in: towards a model of developmental state. The journal of development studies, v. 31, n. 3, p. 400- 427, fev. 1995.

Forms of democratic developmental States. Democratic practices and development capacity. In: ROBINSON. Mark; WHITE, Gordon. (Ed.). The democratic developmental State. Political and institutional design. Oxford: Oxford University Press, 1998.

LIST, George Friedrich. Sistema nacional de economia política. Tradução Luiz João Baraúna. São Paulo: Nova Cultural, 1986.

MIGUEL, Luis Felipe. Impasses da accountability: dilemas e alternativas da representação política. Revista de Sociologia e Política, v. 25, p 25-38, 2005.

NORTH, Douglas. Understanding the process of economic change. London: Institute of Economic Affairs, 1996.

The role of institutions in Economic Development. United Nations Economic Comission for Europe: Geneva, 2003.

PAINTER, Marie; PIERRE, Jean. Unpacking Policy Capacity: Issues and Themes. In: (Ed.), Challenges to State Policy Capacity: Global Trends and Comparative Perspectives, Basingstoke: Palgrave Macmillan, 2005.

PERUZZOTTI, Enrique. Media Scandals and Social Accountability: Assessing the Role of the Senate Scandal in Argentina. In: ; SMULOVITZ, C Enforcing the Rule of Law: social accountability in the new Latin American democracies. Pittsburgo: University of Pittsburgh Press, 2006.

PIRES, Roberto; GOMIDE, Alexandre Ávila. Governança e capacidades estatais: uma análise comparativa de programas federais. Revista de Sociologia e Política (Online), v. 24, p. 121-143, 2016.

PIRES, Roberto Rocha Coelho; VAZ, Alexander Cambraia Nascimento. Para além da participação: interfaces socioestatais no governo federal. Lua Nova, p. 61-91, 2014.

RAMESH, M.; HOWLETT, Michael. Achille's heels of governance: critical capacity deficits and their role in governance failures. Regulation and Governance, 2015.

RAUCH, James; EVANS, Peter. Bureaucratic Strctures and bureaucratic performance in less developed countries. Journal of Public Economics, 2011.

RIBEIRO, Luis Claudio; et al. Science in the developing world: running twice as fast? Computing in Science and Engineering, v. 8, jul. 2006

RODRIK, Dani. Industrial policy for the twenty-first century. In: RODRIK, Dani. (Ed.). One economics, many recipes. Globalization, institutions and economic growth. New Jersey: Princeton University Press, 2004.

RUESCHEMEYER, Dietrich; EVANS, Peter B. The state and economic transformation: toward an analysis of the conditions underlying effective intervention. IN: EVANS, P. B.; RUESCHEMEYER, Dietrich; SKOCPOL, Theda. Bringing the state back in. Cambridge: Cambridge University Press, 1985.

SANTOS, Boaventura de Sousa; AVRITZER, Leonardo. Para Ampliar o Cânone Democrático. In: SANTOS, Boaventura de Sousa. (Org.). Democratizar a Democracia: os caminhos da democracia participativa Rio de Janeiro: Civilização Brasileira, 2002.

SCHUMPETER, J. A. Capitalism, socialism and democracy. Londres: Alien\&Unwin, 1976.

SINTOMER, I. O poder ao povo: júris de cidadãos, sorteio e democracia participativa. Belo Horizonte: UFMG, 2010 .

SKOCPOL, Theda. States and social revolutions: a comparative analysis of France, Russia, and China. Cambridge: Cambridge University Press, 1979. .; AMENTA, Edwin. States and Social Policies. Annual Review of Sociology, v. 12, p. 131-57, 1986. 
SYLLA, Richard. The progressive era and the political economy of big government. Critical Review, v. 5, p. 53157, 1992.

VAZ, Alexander Cambraia Nascimento . Participação política, efeitos e resultados em políticas públicas: notas crítico-analíticas. Opinião Pública, v. 17, p. 163-205, 2011.

. Ação estatal, desenvolvimento e democracia: elementos para uma discussão na contemporaneidade. In: CARDOSO JÚNIOR, José Celso. (Org.). Planejamento Brasil Século XXI: inovação institucional e refundação administrativa:elementos para o pensar e agir. Brasília: IPEA, 2015, (Livro 4).

Capacidades burocráticas e políticas no âmbito da gestão pública: inferindo limites e possibilidades para a gestão pública operacional. Revista Brasileira de planejamento e Orçamento, v. 6, 2016.

VIDAL, Diana Gonçalves. História da educação no Brasil: a constituição histórica do campo (1880-1970). Rev. Bras. Hist., São Paulo, v. 23, n. 45, p. 37-70, jul. 2003

WHITE, Gordon. Constructing a democratic developmental state. In: ROBINSON, Mark; WHITE, Gordon. (Ed.). The democratic political state. Oxford: Oxford University Press, 1998.

YIN, Robert K. Estudo de caso: planejamento e métodos. 2. ed. Tradução Daniel Grassi. Porto Alegre: Bookman, 2001. 


\section{ANEXO A - Roteiro de entrevistas realizadas para coleta de informações dos Programas analisados}

Questões estabelecidas para entrevista com os gestores selecionados.

1. Qual sua relação com o Programa?

2. Você considera um bom Programa de políticas pública? Por quê?

3. Qual sua opinião sobre o desenho do Programa?

4. E qual sua opinião sobre a formatação de implementação?

5. Você considera que sua equipe era suficiente para a gestão do processo?

6. Quais as principais dificuldades enfrentadas na sua equipe?

7. Quando havia um problema específico, como ele era resolvido?

8. Havia algum contato com instâncias de controle social no nível local? Por quê? Como essas instâncias influenciavam o trabalho de sua equipe? E como influenciavam a própria implementação do Programa?

9. Se você pudesse, o que teria mudado no processo? Por quê?

10. Gostaria de fazer alguma observação? 


\title{
Assessing the core of bureaucratic and political capacities: a comparative study of development and impacts in four institutions of the Brazilian Federal Executive
}

\begin{abstract}
The article investigates the institutional constraints for the development of political and bureaucratic capacities by governmental institutions, as well as to what extent and sense the combination of these two elements tends to improve their processes of formulation and implementation of public policies. A comparative study of four institutions of the Brazilian federal executive power is carried out, seeking, through their respective historical paths, explanatory elements for their current situation in terms of the abovementioned capacities. In addition, a study is carried out of programs developed by these institutions themselves, investigating how the current capacity of their institutions tends to influence the development of these programs. The analysis shows that the thematic area of action of the institutions has important influence on their potential of development of the studied capacities. In addition, the joint development of these capacities seems to lead to satisfactory results in the development of policies by each institution.
\end{abstract}

Keywords: state capabilities, bureaucratic capabilities, social-state interfaces, public policy, socioeconomic development.

\section{Cotejando capacidades burocráticas y políticas como acción: un estudio comparativo de desarrollo e impactos en cuatro órganos del Ejecutivo Federal brasileño}

\section{Resumen}

El artículo investiga los condicionantes institucionales para el desarrollo de las capacidades políticas y burocráticas por instituciones gubernamentales, así como en qué medida y sentido la combinación de esos dos elementos impacta sus procesos de formulación vejecución de políticas públicas. Se realiza un estudio comparativo de cuatro instituciones del poder Ejecutivo Federal brasileño, buscando, a través de sus respectivos recorridos históricos de formación, elementos explicativos para su situación actual a partir de esas capacidades. Además, se realiza un estudio de programas desarrollados por esas propias instituciones, entreviendo en qué sentido su estado actual de capacidades tiende a influenciar en el desarrollo de esos programas. El análisis muestra que el área temática de actuación de los órganos tiene una influencia importante en el potencial de desarrollo de las capacidades estudiadas. Además, el desarrollo conjunto de estas últimas parece llevar a la obtención de resultados satisfactorios en el desarrollo de políticas por esos órganos.

Palabras clave: capacidades estatales, capacidades burocráticas, capacidades políticas interfaces socioestatales; políticas públicas, desarrollo socioeconómico. 
